\title{
CONSTRUTIVISMO, PSICOLOGIA EXPERIMENTAL E NEUROCIÊNCIA
}

\author{
Silvio José Lemos Vasconcellos* \\ Simone da Silva Machado**
}

\section{Resumo}

O principal objetivo deste trabalho é discutir a abordagem construtivista e suas relaçôes como algumas descobertas relacionadas à psicologia experimental e à neurociência. $\mathrm{A}$ elaboração do texto está baseada num trabalho de consulta a algumas publicações indexadas no PsycoInfo, bem como em algumas obras que contemplam essas áreas. Os autores argumentam que a eficácia dos diferentes modelos de terapia cognitiva pode ser ampliada por intermédio de um trabalho mais voltado para os aspectos não racionais da cognição. $\mathrm{Na}$ parte final deste artigo, os autores enfatizam a necessidade de transformar o construtivismo numa apropriada metáfora para a terapia cognitiva, sendo que essa asserção está baseada nas afirmações de Meichenbaum (1993).

Palavras-chave: construtivismo, neurociência, psicologia experimental

\section{AbSTRaCt}

\section{CONSTRUCTIVISM, EXPERIMENTAL PSYCHOLOGY AND NEUROSCIENCE}

The main objective of this article is to discuss the constructivism approach and its relations with some discovers related to the experimental psychology and neuroscience. The text was drawn up based on consulting scientific publications indexed in PsycInfo and textbooks related to the mentioned fields. The authors also argument that the effectiveness of different models of

* Psicólogo, Mestre em Ciências Criminais pela Pontifícia Universidade Católica do Rio Grande do Sul e Doutorando em Psicologia do Desenvolvimento pela Universidade Federal do Rio Grande do Sul, Bolsista da Fundação de Aperfeiçoamento de Pessoal de Nível Superior e CAPES.

** Psicóloga, Doutora em Psicologia do Desenvolvimento pela Universidade Federal do Rio Grande do Sul e Professora da UNISC. 
cognitive therapy can be improvement through a work with non-rational aspects of the human cognition. In the final part of this article, the authors emphasize the necessity to transform the constructivism in an appropriate metaphor for the cognitive therapy. This assumption is based on the Meichenbaum's affirmations (1993).

Keywords: constructivism, neuroscience, experimental psychology

\section{INTRODUÇÃO}

Segundo Mahoney (1998), um importante postulado que caracteriza o paradigma construtivista no âmbito da psicologia é a idéia de que o ser humano não é um produtor solitário e auto-suficiente da própria experiência, mas sim o seu co-criador. Greenberg e Pascual-Leone (1995) enfatizam, por sua vez, o papel dinâmico do organismo, num contínuo processo de reorganização da complexidade interna. Guidano (1995) ressalta que a organização da experiência consolida-se a partir de uma progressão ortogenética, onde a própria ordem envolve flutuações.

De um modo geral, a ênfase no caráter auto-organizador e processual da capacidade de interagirmos como organismo está no cerne do enfoque construtivista. Trata-se de ressaltar a corporeidade dos processos cognitivos, bem como o fato de que o processamento de informações para o qual estamos capacitados não ocorre como um evento isolado. Nesse sentido, a avaliação racional não é entendida como condição suficiente para a reorganização da experiência e, sendo assim, a própria psicoterapia deve buscar uma articulação entre os diferentes níveis em que esta se consolida (Neimeyer, 1993).

Este artigo procura, de forma sintética, apresentar uma série de achados significativos na esfera da neurociência e da psicologia experimental que atestam a pertinência de uma abordagem terapêutica que objetive ir além dos processos mais explícitos e racionais. Procura analisar de que forma essas constataçôes acabam contrapondo o entendimento computacional da mente e uma suposta primazia dos processos racionais que a ele costuma estar associada. Não se pretende, por certo, descaracterizar o valor das terapias cognitivas fundamentadas em concepções racionalistas, mas sim evidenciar que tais práticas podem ampliar a sua efetividade, na medida em que tomarem como referência um entendimento mais amplo da própria cognição humana. 


\section{As CIÊNCIAS COGNITIVAS E O FORTALECIMENTO DE ALGUNS PRECEITOS RELACIONADOS A UMA META-TEORIA CONSTRUTIVISTA}

Conforme salientam alguns autores (Eysenck \& Keane, 1994; Miller, 2003; Gardner, 2003), as ciências cognitivas surgem, no final dos anos cinqüenta, como um amplo conjunto de disciplinas fundamentado na possibilidade de realizaremse estudos experimentais sobre uma série de regularidades constitutivas do psiquismo humano. Nesse contexto, o arcabouço teórico denominado "processamento de informações" passou a ser sinônimo de um entendimento computacional da mente (Sternberg, 2000).

Explicar a cognição humana, de acordo com a citada abordagem, é explicar a sintaxe emergente (Megill, 2003). As informaçôes codificadas geram representações que, por sua vez, orientam um processamento seqüencial. Parte-se do pressuposto de que o ser humano pode efetivamente representar a realidade na qual está inserido e que há, nesse processo, uma métrica de correspondência. Nas palavras de Fodor (1968), o pensamento estaria apto a captar o objeto de uma forma específica e determinante. Nesses termos, apregoa-se a funcionalidade dos mecanismos cognitivos com base num entendimento racionalista.

Em um primeiro momento, pode-se enfatizar o fato de que o construtivismo, como uma meta-teoria tributária do próprio avanço das ciências cognitivas, rejeita a premissa de que estejamos aptos a representar a realidade ponto-a-ponto (Mahoney, 1998). Para alguns teóricos, denominados construtivistas críticos, podemos representá-la, mas não através de um mero processo de reprodução. Somos, portanto, os seus co-criadores a partir de uma capacidade holística e dinâmica. Para outros, que, por sua vez, podem ser denominados de construtivistas radicais, conforme Mahoney, não há representações, uma vez que o conhecimento não reflete uma realidade ontológica objetiva e sim um mundo totalmente construído pela experiência.

A citada abordagem rejeita também a idéia de que a sintaxe seja o modo fundamental de organização da experiência e do conhecimento. Dito de outra forma, os significados podem ser indiferentes às regras (Bruner, 1997). Nesses termos, os significados dizem respeito a construçôes pessoais ou, poder-se-ia dizer, consolidadas a partir da experiência. Tal como salienta esse mesmo autor, o significado não é e nem poderia ser o resultado da computação. Computadores podem organizar seu conhecimento sobre o mundo tão somente a partir de ordenamentos sintáticos, seres humanos não.

A elucidação desses pontos torna-se importante para a discussão que se pretende desenvolver. Indubitavelmente, seria possível aludir uma série de outras 
questôes e posiçôes vinculadas a uma compreensão construtivista do funcionamento cognitivo, que, por sua vez, está na base das próprias psicoterapias cognitivoconstrutivistas. Por outro lado, no que diz respeito às pesquisas em psicologia experimental e neurociência que serão referenciadas neste artigo, as convergências mais notáveis vinculam-se a essas mesmas premissas.

\section{ESTUdOS SOBRE OS MECANISMOS PERCEPTIVOS E O PROCESSAMENTO DE INFORMAÇÕES EM SEUS DIFERENTES NÍVEIS}

No que se refere ao modo como processamos as informações ambientais, uma série de pesquisas já vem corroborando o fato de que não há, em muitos casos, uma seletividade deliberada e racionalmente gerenciável nesse mesmo processo. Dito de outro modo, em um nível consciente, não é possível administrar a totalidade dos mecanismos envolvidos no processamento das informações para o qual estamos capacitados (Vasconcellos, 2005). Em certos casos, podemos, portanto, reagir sem que consigamos, de forma efetiva, discriminar.

Exemplos desse funcionamento já foram bem documentados nos trabalhos de Zajonc (1980, 1984), onde uma série de informaçôes apresentadas em um nível subliminar mostrou-se capaz de afetar as avaliaçôes cognitivas subseqüentes. Em experimentos desse tipo, costuma ser apresentado um conjunto de estímulos, cuja exposição ocorre em um período de tempo muito breve e, desse modo, inviabiliza uma deteç̧ão acurada por parte dos sujeitos que se deparam com as informações que estão sendo apresentadas. Conforme Eysenck e Keane (1994), efeitos semelhantes podem ser obtidos a partir da chamada exposição parafoveal, onde a informação não é efetivamente discriminada em um nível consciente, porém, nesse caso, não em decorrência do tempo de exposição, mas sim pelo fato de ser apresentada na periferia do campo visual. Em termos gerais, esses processos podem ser, de acordo com Bargh e Chartland (1999), denominados de processos automáticos, sendo que a ocorrência dos mesmos é capaz de afetar uma diversidade de mecanismos avaliativos simples ou mesmo julgamentos que envolvam a consideração sobre diferentes variáveis.

Os trabalhos de Bargh (1982) contemplando o processamento parafoveal de informações mostraram que a visualização não consciente de palavras que denotavam agressividade fez, por si só, com que os sujeitos a elas expostos demonstrassem uma maior tendência para identificar hostilidade em cenas específicas quando comparados a grupo controle. Numa outra pesquisa desenvolvida por Devine (1989), foram utilizadas palavras cujo significado estava associado, de forma indireta, a certos estereótipos dirigidos a indivíduos afro-americanos e supostamente 
vinculados à delinqüência, tais como "gueto", "preguiça”, "minoria”, "desemprego". Do mesmo modo que a pesquisa aludida anteriormente, foi possível observar o mesmo tipo de tendência no que diz respeito aos juízos emitidos sobre determinados sujeitos após o processamento não consciente dessas informações. De um modo geral, pode-se dizer que pesquisas desse tipo acabaram evidenciando a existência de uma espécie de preconceito não conscientemente detectável por parte dos sujeitos avaliados.

Em um nível subliminar, é também possível comprovar que o processamento de outros tipos de estímulos tais como expressões faciais mostra-se capaz de gerar reações específicas (Bargh, Chen \& Burrows, 1996). Outros estudos comprovam que o desempenho em tarefas de memória pode ser igualmente afetado pelo processamento não consciente de informações (Zelli, Huesmann \& Cervone, 1995; Zelli, Cervone \& Huesmann, 1996).

Estudos no campo da neurociência e da psicopatologia também evidenciam uma série de tendências relativas aos mecanismos de percepção que se mostram incongruentes com a perspectiva racionalista. Ao estudar pacientes portadores da chamada síndrome de Charles Bonnet, Ramachandran (2002) sugere que a formação de imagens mentais está significativamente baseada numa espécie de complementaridade conceitual. Em outras palavras, o citado pesquisador ressalta que as ilusões perceptivas presentes na síndrome referem-se a um agravamento da capacidade normal do cérebro para consolidar percepçôes não apenas a partir das informaçôes detectadas externamente. Também na esfera da neurociência, destacam-se os trabalhos com pacientes que tiveram a área V1 do cérebro comprometida por lesões, preservando, entretanto, a funcionalidade da área V5. Nesse caso, estudos mostram que a presença de obstruções em certas partes do campo visual não impede que pacientes desse tipo consigam emitir julgamentos discriminatórios sobre estímulos apresentados na área cega (Weiskrantz, 1986, 1990).

De um modo geral, os estudos envolvendo os mecanismos perceptivos humanos fundamentam duas importantes constatações. Pode-se, a partir deles, presumir que o aparato cognitivo humano envolve um processamento de informação amplo e capaz de abarcar níveis mais sutis que, dessa forma, não seriam plenamente suplantados pela nossa capacidade analítica consciente. Esse tipo de sutileza é também constatável nas pesquisas que envolvem a detecção de estímulos auditivos, sendo que, nesse caso, comprova-se uma tendência para que estímulos emocionalmente carregados sejam detectados com um maior grau de dificuldade do que estímulos neutros (Hardy \& Legge, 1968). Tal como afirmam Greenberg e Pascual-Leone (1995) ao destacarem o caráter construtivo dos processos que perfazem a cognição, o ser humano é um processador em múltiplos níveis. 


\section{SINTAXE, SEMÂNTICA E A ORGANIZAÇÃo DO CONHECIMENTO}

No que se refere à forma como organizamos o nosso conhecimento sobre o mundo e sobre nós mesmos, duas concepçôes, na esfera das ciências cognitivas, podem ser claramente diferenciadas entre si. De um lado, o entendimento de que a sintaxe é a forma essencial que perfaz essa mesma organização. De outro, a idéia de que a capacidade humana para gerar significados particularizados pode ser alheia à própria sintaxe.

No primeiro caso, tem-se uma compreensão que é totalmente tributária dos estudos em ciências cognitivas, principalmente no período do seu advento e do seu fortalecimento como uma nova forma de conceber e estudar o psiquismo humano. Dito de outro modo, trata-se de pressupor que o pensamento, em última instância, abarca um amplo conjunto de regras ou, poder-se-ia dizer, diz respeito a um software específico funcionando em um hardware específico (Pinker, 1999). Nesse sentido, alterá-lo, em suas diferentes instâncias, equivale a alterar a informação e os seus respectivos transcursos. Entretanto, o que significa não postular a sintaxe como uma forma essencial de organização do conhecimento?

Para que se responda a citada questão, pode-se, num primeiro momento, considerar os chamados modelos conexionistas ou o assim chamado funcionalismo neurocomputacional (Teixeira, 1997; 1998). Embora, como bem destaque Mahoney (1998), não exista um conexionismo unificado, uma idéia mais geral sobre essa abordagem refere-se ao fato de que a mente é entendida como um associador de padrōes e não exatamente como um manipulador de símbolos como no caso dos modelos sintáticos e representacionalistas (Frawley, 2000). A ênfase, nesse caso, recai sobre os padrões de neuroconectividade, sendo que, com base nesses postulados, torna-se possível explicar o caráter mais dinâmico e, ao mesmo tempo, particularizado que perfaz o funcionamento cognitivo (Vasconcellos, no prelo).

Embora, tal como saliente Andler (1998), alguns modelos conexionistas possam pressupor microrrepresentações baseadas em regras, o fato é que, a partir deles, enfatiza-se uma dialética maior entre indivíduo e ambiente. Nesses termos, para a referida abordagem, a organização do conhecimento não equivale a uma série de ordenamentos sintáticos e, nesse caso, os significados particularizados da experiência tornam-se, até certo ponto, passíveis de uma modelagem computacional. Esse seria, portanto, um notório exemplo de modelo que se fortalece no âmbito das próprias ciências cognitivas, sem apregoar a capacidade sintática como um aspecto recorrente e fundamental para a organização do conhecimento.

Um outro modelo que acaba por refutar a sintaxe como forma essencial de organização do conhecimento, embora, sob alguns aspectos, também refute as 
modelagens conexionistas, é o assim chamado darwinismo neural (Edelman, 1992). Para o citado autor, explicar a forma como organizamos o conhecimento sobre o mundo e sobre nós mesmos é explicar a consciência em níveis diferenciados. Ou seja, uma consciência primária, bem como uma consciência elaborada que se fez possível a partir da própria filogênese.

Dentro dessa perspectiva, a capacidade humana para conceitualizar surge atrelada a um sistema de valor límbico-troncular que está, por sua vez, no cerne da consciência primária. A consciência elaborada, de outro modo, só aparece na espécie quando os centros conceituais passam a categorizar acontecimentos ordenados que se sucedem em atos de fala. Nesse sentido, a sintaxe é então alcançada em caráter secundário.

De forma mais sintética, pode-se dizer que, dentro desse entendimento, a capacidade humana para gerar conceitos vincula-se à própria capacidade para atribuir valor distintivo num processo que envolve áreas subcorticais diretamente vinculadas a uma responsividade emocional. Nesses termos, o cérebro, antes de ser um sistema sintático, é um sistema semântico-valorativo. Conforme salienta o próprio Edelman (1992), o seu trabalho tem como objetivo fornecer uma base biológica para a teoria construtivista dos significados desenvolvida por Jerome Bruner, teoria essa que ressalta o caráter particularizado da experiência com base em um processo narrativo em constante atualização (Bruner, 1998).

Para além dessas questões, Edelman (1992) postula que, em um nível neuronal, uma ampla reprodução diferencial acaba sendo a condição necessária para a evolução e uma ampliação diferencial viabilizaria a seleção de grupos específicos. Uma vez enfatizada essa diversidade anatômica e o conseqüente darwinismo que se mostra capaz de consolidar a consciência em níveis distintos, o citado autor afirma que um dinamismo desse tipo seria, em termos computacionais, irreplicável.

Em termos gerais, o modo como o conhecimento está organizado em nossas mentes e as possibilidades de acessar os diferentes níveis de estruturação da experiência tornam-se questões salutares no processo terapêutico. Uma vez apresentados alguns postulados específicos, bem como os resultados de determinados estudos experimentais voltados para o modo como os seres humanos processam e organizam as informações, passaremos a discutir a implicação dessas questôes para a prática clínica em seus diversos aspectos.

\section{As INTERVENÇŌES TERAPÊUTICAS E A PERTINÊNCIA DE UMA METÁFORA CONSTRUTIVISTA}

De acordo com Meichenbaum (1993), o construtivismo pode também apresentar-se como uma terceira metáfora para orientar as terapias cognitivo-com- 
portamentais. Nesse sentido, a proposta construtivista pode ser bem mais do que um simples agrupamento de métodos específicos relacionados à intervenção terapêutica. A partir dela, torna-se possível uma maior abrangência para as próprias terapias cognitivas racionalistas, na medida em que os diferentes níveis de organização da experiência sejam também contemplados. Para fins de análise, mostra-se oportuno discorrer sobre tais possibilidades, que, sob muitos aspectos, estão também relacionadas aos estudos revisados.

Em termos gerais, as sólidas evidências de que um processamento automático de informaçôes seja possível não atestam que, em um nível metacognitivo, intervenções no que diz respeito às conseqüências desse mesmo processamento não possam ocorrer. Dito de outro modo, uma coisa seria afirmar que podemos ser reativos às informações processadas em um nível não consciente, outra coisa seria afirmar que a testagem lógica dos pensamentos, que é, por sua vez, uma premissa fundamental dos modelos racionalistas, não poderia retroagir sobre essa mesma reatividade. Nesses termos, conforme salientam Beck e Alford (2000), pesquisas que evidenciam a automaticidade da cognição não chegam a contrapor a própria efetividade das terapias cognitivas em seus modelos mais racionalistas. No entanto, o que as pesquisas sobre o processamento automático das informações podem realmente sugerir?

Um primeiro aspecto que merece ser ressaltado refere-se ao elevado grau de sutileza que caracteriza o nosso funcionamento cognitivo em seus diferentes níveis. Sutileza, nesse caso, implica que a própria organização da experiência pode, em muitos casos, prescindir de uma capacidade discriminatória acurada. No que se refere à prática clínica, poder-se-ia dizer então que outras linguagens tornam-se possíveis e recorrentes. Linguagens que não são exclusivamente enfatizadas pelo construtivismo, mas que, no entanto, adquirem para esse paradigma um valor crucial. Não se trata, portanto, de afirmar que processamentos subseqüentes e simbolicamente mediados não possam ser intervenientes. Trata-se, por outro lado, de afirmar que, diante do próprio automatismo que caracteriza a cognição, intervenções pré-cognitivas podem revelar uma eficácia precedente.

Questôes de automatismo estão também relacionadas com os trabalhos de LeDoux (1996). Para o referido neurocientista, em um nível mais sutil, situações podem ser percebidas e registradas através de uma via secundária que, segundo suas palavras, passaria ao largo do neocórtex. A idéia principal é de que uma via talâmica para o corpo amigdalóide não seja apenas uma espécie de relíquia evolutiva, mas sim um sistema diretamente responsável pelo aprendizado emocional que ocorre de forma rápida e sem depender de deteç̧ôes acuradas ou mesmo de uma ponderação por intermédio da capacidade lingüística. Se nos remetermos ao contexto da terapia como uma situação de aprendizado, é possível então concluir 
que esse mesmo aprendizado pode ocorrer por caminhos diferenciados, sendo que muitos deles dizem respeito às relações vinculares relacionadas à própria díade formada por paciente e terapeuta. Conforme ressalta Mahoney (1998), o trabalho terapêutico deve contemplar as razões, os rituais e o relacionamento.

De acordo com essa perspectiva, pode-se entender também que a racionalidade, em seus aspectos mais elementares, é uma via de intervenção, mas estaria longe de ser a única. Se é correto afirmar que o conhecimento sobre nós mesmos e sobre as situações que experimentamos não está, na sua totalidade, organizado por intermédio de uma sintaxe funcional, então outras formas de reestruturação desse mesmo conhecimento devem ser buscadas. Nesses termos, significados podem ser preconizados e a reorganização dos mesmos não dependeria apenas de uma recursividade lógica.

Nessa perspectiva, não há uma negação da sintaxe. $\mathrm{O}$ pensamento pode, em última instância, estar parcialmente organizado em torno dessa capacidade. Tal idéia é também compatível com a crítica feita por Fodor e Pylyshyn (1988) de que as modelagens conexionistas não se mostrariam aptas a explicar uma série de propriedade sintáticas e composicionais do pensamento humano. No que diz respeito às ciências cognitivas, é possível que as chamadas arquiteturas híbridas que incorporam achados das duas correntes mostrem-se mais promissoras quanto a uma modelagem aproximativa dos mecanismos cognitivos (Vasconcellos, 2005). No entanto, a questão principal refere-se ao fato de que a própria sintaxe parece ser tão somente uma capacidade sobreposta, mas não ubíqua no que diz respeito à cognição humana. Mesmo alguns defensores ferrenhos da visão computacionalista, como é o caso de Pinker (1991; 1999), propõem uma revisão de certos postulados chomskyanos e ressaltam o papel central da semântica e da fonologia. Questões como essas nos fazem pensar que, tal como salienta Edelman (1992), um racionalismo do significado mostre-se insustentável.

No contexto clínico, a importância dessas questôes refere-se ao fato de que encorajar o paciente a consolidar outras narrativas que explorem, dessa forma, novos significados pode representar também um recurso para certas abordagens terapêuticas centradas na racionalidade. Com base nessa asserção, pode-se entender que as próprias avaliaçóes racionais poderiam mostrar-se mais efetivas quando conjugadas com um contexto oportuno relacionado à exploração dos significados.

De um modo geral, os estudos relativos à neurociência e à psicologia experimental que foram destacados nesse artigo mostram-se verdadeiramente sugestivos quanto ao fato de que o funcionamento cognitivo humano é apenas parcialmente explicável pela visão computacionalista. Em parte, isso se deve ao fato de que esse mesmo funcionamento diz respeito a um substrato neurobiológico cuja efetividade não poderia se dar tão somente a partir de mecanismos de instrução. 
Num sistema que não funciona tão somente a partir de instruções, um olhar voltado para os seus aspectos mais dinâmicos e estruturais tem muito a oferecer. Trata-se, portanto, de contemplar outras formas de organização do conhecimento e da experiência e não somente aquelas passíveis de uma explicitação sintática. No que se refere ao processo terapêutico, pode-se dizer então que a lógica atua, mas não prepondera e, sendo assim, o construtivismo pode, tal como sugere Meichenbaum (1993), apresentar-se como uma nova e promissora metáfora.

\section{CONSIDERAÇÕES FINAIS}

Este artigo objetivou revelar a pertinência da meta-teoria construtivista para que uma maior abrangência e efetividade, no âmbito das diferentes terapias cognitivas, torne-se possível. Procurou também evidenciar que uma compreensão mais ampla sobre os processos cognitivos humanos vincula-se a uma série de estudos na esfera da psicologia experimental e da neurociência. Nesse sentido, o próprio avanço das ciências cognitivas, em suas diferentes facetas, encarregou-se de mostrar que o ser humano é um processador em múltiplos níveis e que o aparato que consolida os diferentes mecanismos cognitivos caracteriza-se por uma notória capacidade de auto-organização.

Em termos gerais, o artigo procurou discutir ainda a capacidade humana de conferir ordenamentos sintáticos à própria experiência e as suas respectivas relações com a organização do conhecimento em níveis bastante diferenciados. Uma vez que interferir na organização desse mesmo conhecimento é o objetivo maior de todo e qualquer processo terapêutico, procurou-se discutir algumas questóes relacionadas a essas possibilidades. De um modo sintético, o artigo procurou enfatizar que a capacidade lógica e analítica do pensamento não demonstra possuir uma primazia sobre todos os demais processos. Faz-se necessária, no que diz respeito às próprias intervenções terapêuticas, a exploração de outros níveis de consolidação da experiência, além daqueles que se mostram mais passíveis de uma ponderação lógica. Enfatizar essa necessidade não é o mesmo que descaracterizar o valor da racionalidade no que se refere ao processo terapêutico, mas é, de outro modo, evidenciar que certas mudanças podem ser mais bem consolidadas quando conseguem atingir os diferentes níveis de organização da experiência.

\section{REFERÊNCIAS BIBLIOGRÁFICAS}

Andler, D. (1998). Cálculo e representação: as fontes. Em Andler, D. (Org.) Introdução às ciências cognitivas (pp. 25-54). São Leopoldo: Editora Unisinos. 
Bargh, J. A. (1982). Attention and automaticity in the processing of self-relevant information. Journal of Personality and Social Psychology, 49, 1040-1053.

Bargh, J. A. \& Chartland, T. L. (1999). The unbearable automaticity of being. American Psychologist, 54, 7, 462-479.

Bargh, J. A., Chen, M.\& Burrows, L. (1996). Automaticity of social behavior: direct effects of trait construct and stereotype priming on action. Journal of Personality and Social Psychology, 71, 230-244.

Beck, T. A. \& Alford, B. A. (2000). O poder integrador da terapia cognitiva. Porto Alegre: Artmed.

Bruner J. (1997). Atos de significação. Porto Alegre: Artes Médicas.

- (1998). Realidade mental e mundos possiveis. Porto Alegre: Artes Médicas.

Chen, M. \& Bargh, J. A. (1999). Nonconscious behavioral confirmation processes: the self-fulfilling consequences of automatic stereotype activation. Journal of Experimental Social Psychology, 71, 464-478.

Damásio, A. R. (2000). O mistério da consciência. São Paulo: Companhia das Letras.

Devine, P. G. (1989). Stereotype and prejudice: their automatic and controlled components. Journal of Personality and Social Psychology, 56, 680-690.

Edelman, G. M. (1992). Biologia da consciência: as raizes do pensamento. Lisboa: Instituto Piaget.

Eysenck, M. W. \& Keane, M. T. (1994). Psicologia cognitiva: um manual introdutório. Porto Alegre: Artmed.

Fodor, J. (1968). Psychological explanation. New York: Random House.

Fodor, Z. W. \& Pylyshyn, J. (1988). Connectionism and cognitive architecture: a critical analysis. Cognition, 28, 3-17.

Frawley, W. (2000) Vygotsky e a ciência cognitiva - Linguagem e integração das mentes social e computacional. Porto Alegre: Artmed.

Gardner, H. (2003). A nova ciência da mente. São Paulo: Edusp.

Greenberg, L. \& Pascual-Leone, J. (1995). A dialectical constructivist approach to experiential change. Em Neimeyer, R. A. \& Mahoney, M. J. (Orgs.). Constructivism in psychotherapy (pp. 169-191). Washington DC: American Psychological Association Press. Guidano, F. V. (1995). Self-observation in constructivist psychotherapy. Em Neimeyer, R. A. \& Mahoney, M. J. (Orgs.). Constructivism in psychotherapy (pp. 25-35). Washington DC: American Psychological Association Press.

Hardy, G. R. \& Legge, D. (1968). Cross-modal induction of changes in sensory thresholds. Quarterly Journal of Experimental Psychology, 20, 20-29.

LeDoux, J. (1996). The emotional brain. Nova York: Simon \& Schuster.

Mahoney, M. J. (1998). Processos humanos de mudanças - as bases cientificas da psicoterapia. Porto Alegre: Artmed. 
Megill, J. L. (2003). What role do the emotions play in cognition: towards a new alternative to cognitive theories of emotion. Consciousness and Emotion, 40, 81-100.

Meichenbaum, D. H. (1993). Changing conceptions of cognitive behavior modification: retrospect and prospect. Journal of Consulting and Clinical Psychology, 61, 202-204.

Miller, G. A. (2003). The cognitive revolution: a historical perspective. Trends in Cognitive Sciences, 7, 141-144.

Neimeyer, R. A. (1993). An appraisal of constructivist psychotherapies. Journal of Consulting and Clinical Psychology, 61, 221-234.

Pinker, S. (1991). Rules of Language. Science, 253, 530-535. . (1999). Como a mente funciona. São Paulo: Companhia das Letras.

Ramachandran, V. S. (2002). Fantasmas no cérebro. Rio de Janeiro: Record.

Sternberg, J. R. (2000). Psicologia cognitiva. Porto Alegre: Artmed.

Teixeira, J. F. (1997). Filosofia da mente e inteligência artificial. Campinas: Centro de Lógica e Epistemologia da UNICAMP.

. (1998). Mentes e máquinas: uma introdução à ciência cognitiva. Porto Alegre: Artes Médicas.

Vasconcellos, S. J. L. (2005). A mente entreaberta: reflexôes sobre o que a psicologia científica anda pensando sobre o nosso pensar. Rio de Janeiro: Ciência Moderna.

Vasconcellos, S. J. L. (no prelo). Mente, cérebro e representações. Estudos de psicologia, 32.

Weiskrantz, L. (1986). Blindsight: a case study and its implications. Oxford: Oxford University Press.

. (1990). Blindsight. Em M. W. Eysenck (Org.), The Blackwell dictionary of cognitive psychology (pp. 20-25). Oxford: Blackwell.

Zajonc, R. B. (1980). Feeling and thinking: preferences need no inferences. American Psychologist, 35, 151-175.

- (1984). On the primacy of affect. American Psychologist, 39, 117-123.

Zelli, A., Huesmann, L. R. \& Cervone, D. (1995). Social inference and individual differences in aggression evidence for spontaneous judgments of hostility. Aggressive Behavior, 21, 405-417.

Zelli, A., Cervone, D., \& Huesmann, L. R. (1996). Behavioral experience and social inference: individual differences in aggressive experience and spontaneous versus deliberate trait inference. Social Cognition, 14, 165-190.

Recebido em 23 de fevereiro de 2006 Aceito para publicação em 29 de março de 2006 